\title{
Biological Control by Nematophagous Fungi for Plant-parasitic Nematodes in Soils
}

\author{
Jun-hyeong Park, Sun-jung Kim, Jin-ho Choi, Min-ho Yoon, \\ Doug-young Chung, and Hye-Jin Kim*
}

\author{
Departmnet of Bio-environmental Chemistry, College of Agriculture and Life Science, \\ Chungnam National University Daejeon Korea 305-764
}

\begin{abstract}
Envioronmental concerns by use of chemical pesticides have increased the need for altemative method in the control of plant-parasitic nematodes. Biological control is considered eco-friendly and a promising altemative in pest and disease management. A wide range of organisms are known to be effective in control of plant-parasitic nematodes. Fungal biological control is a hopeful research area and there is constant attention in the use of fungi for the control of nematodes. In this review, plant-parasitic nematodes with reference to soils and biological control and nematophagous fungi are dicussed.
\end{abstract}

Key words: Biological control, Nematophagous fungi, Plant-parasitic nematodes, Soil

\section{Introduction}

Nematodes, water-filled pore spaces in the soil where organic matter, plant roots, and resources are most plentiful, are microscopic, worm-like organisms that inhabit water films. nematode, most abundant in the upper soil layers, generally ranges from one to ten million individuals $\mathrm{m}^{-2}$ (Peterson and Luxton, 1982; Lavelle and Spain, 2001). Nematodes which contribute to various functions within the soil system can improve nutrient mineralization such as a $\mathrm{N}$ immobilization (Ferris et al., 1998) while some of them generates diseases in plants (Koenning et al., 1999).

Biological control is an environmentally sound and effective means of reducing or mitigating pest and pest effects through the use of natural enemies whereas chemical methods ,serious hazard to the ecological balance in the course of time, have been mostly used to control nematodes. Therefore, biological control agents are considered as important methods on the field of Nematode management (Sharon et al., 2001).

Numerous microorganisms are known as antagonists of plant-parasitic nematodes (Poinar and Jansson, 1988)

\footnotetext{
Received : January 20. 2012 Accepted : February 9. 2012

*Corresponding author : Phone: +82428216739

E-mail: verylongleg@nate.com
}

but most interest has been focused on nematophagous fungi, especially those that restrain their hosts with specialized traps (Kerry, 1990). Since the discovery of nematode-trapping fungi (Linford and Yap, 1939), a lot of study about nematophagous fungi had been conducted and still has been carrying out for nematocidal agents. In this paper, recent advances in the field of biological control of plant-parasitic nematodes with nematophagous fungi will be evaluated.

Soil condition for plant-parasitc nematodes The nematodes existed for an estimated one billion years become one of the most ancient and diverse types of animals on earth (Wang et al. 1999). The first described plant parasitic nematodes were discovered in wheat seeds (Needham, 1743). The total classification system of nematoda is as shown in Figure 1.

Plant-parasitic nematodes which are too tiny to be distinguished without a microscope develop through 6 stages - an egg stage, 4 juvenile stages, and an adult stage. It is known that the root knot nematode survives each season primarily as eggs in the soil (Perry, 2010).

High nematode density are generally discovered in moist and sandy soils because they contain plentiful pores large enough to accommodate the swimming activities of these highly mobile creatures. The nematodes survive by coiling up onto a cryptobiotic or resting 


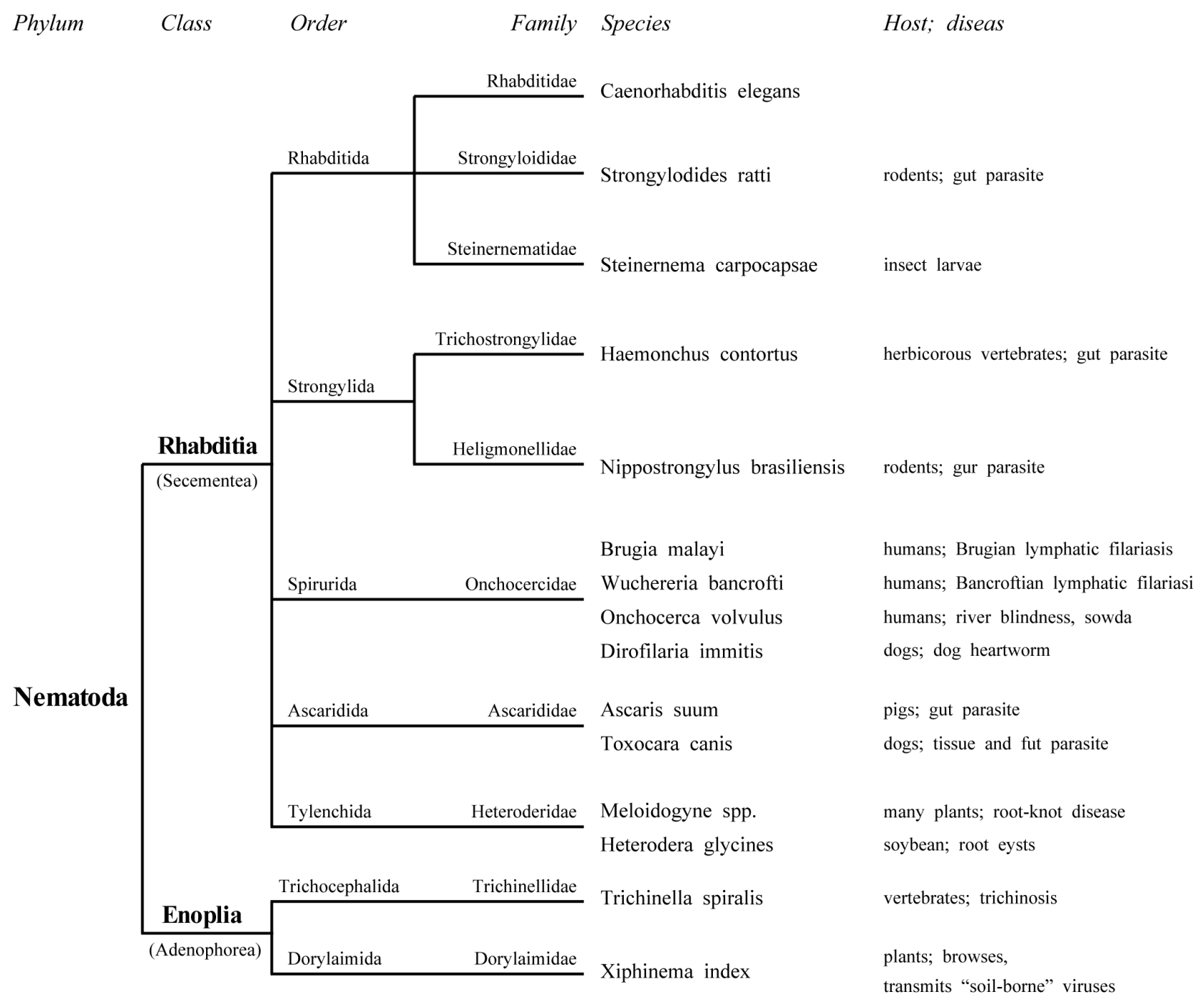

Fig. 1. Classification of Plant-parasitic nematodes.

state when the large soil pores are dehydrated. In semiarid range lands, nematode activity has been shown to be largely limited to the first few days after each rainfall that awakens the nematodes from their cryptobiotic state (Brady and Weil, 2003). Plant-parasitic nematodes can live in soils over wide ranges of $\mathrm{pH}$ so some of them can actually be employed as biological indicators of low $\mathrm{pH}$ soils (Werner et al., 2009).

\section{Fundamentals of biological control and exploitation} of nematophagous fungi Biological control of pests in agriculture is a method of controlling pests that relies on predation, parasitism, herbivory, or other natural mechanisms. It can be an influential component of integrated pest management (IPM) programs. Parasitoids are species whose maturity develops on or within a single insect host, ultimately killing or lethally infecting the host. Pathogens such as bacteria, fungi, and viruses are infection-causing organisms, and kill or weaken their own host and are relatively particular.

Nematologists have identified natural enemies with various mode of action similar to those currently investigated by plant pathologists for the control of soil-borne diseases. Several organisms that are effective as natural enemies of nematodes in the field may have constricted potential as biological control agents for application by cultivators. For example Nematophthora gynophila is a general agent of cereal-cyst nematode decline in many soils, but its potential use is too limited to ensure further development as a biological control agent.

Nematophagous fungi, approximately 160 species, are natural enemies of nematodes. Plant-parasitic nematodes such as root-knot and cyst nematodes are global pests in agriculture and horticulture, causing severe yield losses. They comprise three main groups of fungi: 
the nematode trapping and the endoparasitic fungi that attack vermiform living nematodes by using specialized structures in all sorts of soil environments where they survive mainly as saprophytes (Hertz et al., 2006), and the egg- and cyst-parasitic fungi that attack these stages with their hyphal tips (Greg et al., 2000). One important aspect of nematophagous fungi is the possibility of using them for biological control of

Table 1. Some important genera of nematophagous fungi.

\begin{tabular}{|c|c|}
\hline Genera of Fungi & Genus of Fungus \\
\hline Tarichum & Meristacrum \\
\hline Entomophthora & Myzocytium \\
\hline Isaria & Phytophthora \\
\hline Cylindrocarpon & Trichosporan \\
\hline Anixiopsis & Monacrosporium \\
\hline Colletotrichum & Microdochium \\
\hline Margarinomyces & Trichothecium \\
\hline Monotospora & Dactylella \\
\hline Penicillium & Harposporium \\
\hline Phoma & Metarhizium \\
\hline Phialophora & Cladosporium \\
\hline Pseudeurotium & Ulocladium \\
\hline Verticillium & Dactylaria \\
\hline Cephalosporium & Epicoccum \\
\hline Catenaria & Scytalidium \\
\hline Paecilomyces & Acremonium \\
\hline Nematophthora & Preussia \\
\hline Neocosmospora & Acrophialophora \\
\hline Chaetomium & Allomyces \\
\hline Gliocladium & Coniothyrium \\
\hline Stagnospora & Cystopage \\
\hline Thielavia & Macrobiotophthora \\
\hline Fusarium & Rhopalomyces \\
\hline Pseudopopulospora & Stylopage \\
\hline Arthrobotrys & Mortierella \\
\hline Chaetopsinea & Trichocaldium \\
\hline Diheterospora & Botryotrichum \\
\hline Monocillium & Drechmeria \\
\hline Olpidium & Hirsutella \\
\hline Rhizopus & Nematoctonus \\
\hline Trichoderma & Aspergillus \\
\hline Humicola & Pleurotus \\
\hline \multicolumn{2}{|l|}{ Aphanomyces } \\
\hline \multicolumn{2}{|l|}{ Lagenidium } \\
\hline Leptolegnia & \\
\hline
\end{tabular}

plant-parasitic nematodes. Owing to the ban of many nematicides due to health and environmental concerns, new alternatives for nematode control are therefore needed. Biological control may be such an alternative. Some important genera of fungi that are known to restrain nematode multiplication by parasitism, predation or antagonism are shown in Table 1.

Mode of action by three types of nematophagous fungi The fungi involved in the biological control of nematodes are generally of three types; i.e. predator, into (i) endoparasitic fungi, (ii) predacious fungi, (iii) opportunistic fungi. The specific description for three types of fungi is below.

\section{Endoparastic fungi}

The knowledge of endozoic nematophagous fungi has been increased remarkably during the last few decades. However, very few of these fungi have been considered crucially as potentially useful agents for biocontrol. The biology of most endoparasitic fungi is not clearly understood, and isolation of the pure culture is a little difficult since the are obligatory in nature.

\section{Predacious fungi}

The nematode trapping fungi form more rings to fix the nematode, or stuck then on an adhesive substance, or to constrict them using the rings in the presence of nematodes than in their absence. Many attempts have been made to assess their potential as biocontrol agents of plant-parasitic nematodes. It is mainly attributed to the facts that the soil environment can be altered to favor them and that their activity can be enhanced through organic amendments to soil. They create extensive network of hyphae and also trapping devises at intervals along hypha for catching nematodes. These traps catch nematodes either mechanically or by adhesion, later fungi penetrates into the nematode body to feed on the body contents. They are known to construct six types of traps as shown in Table 2 .

\section{Opportunistic fungi}

Opportunistic fungi can colonize nematode reproductive structures and have the capability to deleteriously affect them. Nematodes belonging to the Heteroderid group and at the sedentary stages of their 
Table 2. Six types of traps of nematophagous fungi.

\begin{tabular}{ll}
\hline \hline Type & Description \\
\hline Type A & Adhesice hyphae, non-modified-Stylopage spp. \\
three-dimensional adhesive nets - Arthrobotrys conoides, \\
Type B & A. oligospora, A. robusta, A. arthrobotryoides. \\
Type C & Adhesive knobs - Dactylella doedycoides. \\
Type D & Non-constricting rings - Dactylaria candida, D. thaumasia, D. eudermata \\
Type E & Constricting rings - Dactylaria brachophaga \\
\hline
\end{tabular}

life-cycle are vulnerable to be attacked by these fungi either within the host roots or when exposed on the root surface or within the soil. The development of these fungi is known to be enhanced in the rhizosphere. Typically these fungi have a better role in biological control of nematodes than the two earlier groups discussed.

Nematicidal substances from fungi Though no major commercial product based on these natural fungal compounds has been developed yet for wide use, many nematicidal compounds have been found from fungi. There are several compounds from fungi which are substances to have a nematicidal activity. Alkaloids group of compounds included 33 nematicials from fungi. Peptide group of nematicidal compounds includes 26 chemicals and there are 35 fungal compounds in case of terpenoids. Up to now, no major commercial product based on nemato-toxic fungi or their metabolites has been developed yet.

Mass production and formulation of nematophagous fungi Endoparasitic fungi generally have insufficient growth outside the nematode host (Barron, 1977). Liquid culturing of fungi for mass production of spores and mycelium has often been considered ideal for biological control (Papavizas et al., 1984). Production of large amounts of these fungi has an advantage as a biocontrol agent because they do not depend on an a nutrious source. Commercial fermentation technology has to be advanced to produce mass inocula (Kenney \& Couch, 1981).

Granular formulation is generally considered to be the most fit for microorganisms that are to be applied to soil. there has been substantial interest in encapsulating biological control agents such as sodium alginate (Fravel et al., 1985). Kerry (1988) demonstrated that hyphae of $\mathrm{V}$. chlamydosporium grew approximately $1 \mathrm{~cm}$ from alginate-bran granules and suggested that a granular formulation may be suitable for this species. Diatomaceous earth granules impregnated with $10 \%$ molasses, lignite-stillage granules and alginate-clay pellets have totally proved suitable carriers for biological control agents (Backman \& Rodriguez-Kabana, 1975; Jones et al., 1984; Fravel et al., 1985). Matskievich et al. (1990) suggested biopreparation of Arthrobotrys spp. on composted strawmanure, turf-manure, sawdust manure and other materials. These formulations produced a network of traps in soil.

\section{Conclusions}

Although a large number of fungi have been reported to reduce nematode density, only a few of them have demonstrated their efficacy as efficient parasites of nematodes. Even the efficient parasites do not have totally the desired characteristics of a good biological control agent. The nematophagous fungi difficult to culture in mass production have a need to make up for two defective points. More importantly, the impact of the soil environment, host plant and nematode should be tested as these are likely to affect the efficacy of the biological control agent, and could account for the lack of activity of potential agents in specific test conditions.

\section{References}

Backman, P.A. and Rodriquez-Kabana, R. 1975. A system for growth and delivery of biological control agents to the soil. Phytopathology. 65:819-821.

Barron, G.L. 1977. The nematode Destroying Fungi. Topics in Microbiology No. 1. Canadian Biological Publications, Guelph/ Ontario, Canada.

Brady, N.C. and R.R. Weil. 2003. Elements of the Nature and 
Properties of Soils (2nd Edition). Upper Saddle River, NJ: Prentice-Hall, Inc.

Ferris, H., R.C. Venette, H.R. van der Meulen, and S.S. Lau. 1998. Nitrogen mineralization by bacterial-feeding nematodes: Verification and measurement. Plant and Soil. 203:159-171.

Fravel, D.R., Marois, J.J., Lumsden, R.D., and Connick, W.J. Jr. 1985. Encapsulation of potential biocontrol agents in an alginate clay matrix. Phytopathology. 75:774-777.

Gregory, W.F., Atmadja, A.K., Allen, J.E., and Maizels, R.M. 2000. The abundant larval transcript $1 / 2$ genes of Brugia malayi encode stage-specific candidate vaccine antigens for filariasis. Infect. Immun. 68:4174-4179.

Jones, R.W., Petlit, R.E., and Taber, R.A. 1984. Lignite and stillage: carrier and substrate for application of fungal biocontrol agents to soil. Phytopathology. 74:1167-1170.

Kenney, D.S. and Couch, T.L. 1981. Mass production of biological agents for plant disease, weed and insect control. In Biological Control in Crop Production (BARC Symposium No. 5), ed. G.C. Papavizas. Allenheld and Osmum. Totowa. pp.143-150.

Kerry, B.R. 1988. Fungal parasites of cyst nematodes. Agriculture Ecosystems and Environment. 24:293-305.

Kerry, B.R. 1990. Assessment of progress towards microbial control of plant-parasitic nematodes. Journal of Nematology. 22:621-631.

Koenning S.R., Overstreet, C., Nonling, J.W., Donald, P.A., Becker, J.O., and Fortnum, B.A. 1999. Survey of crop losses in response to phytoparasitic nematodes in the United States for 1994. J. Nematol. 31:587-618.

Lavelle, P. and A.V. Spain. 2001. Soil ecology. Kluwer Academic Publishers, Boston, MA.

Linford, M.B. and Yap, F. 1939. Phytophthol. 29:596.

Matskievich, N. V., Kosovets, V. S., Iosseliani, D. A., Karapetyan, D. A., Prikhos'ko, V. F., Udalova, V. B. \& Tedlyakova, T. V.
(1990). Characterization of nematophagous properties of biopreparation of predatory fungi, obtained by an experimental industrial method. Mikologiya i Fitopatologiya, 24, 22-26.

Needham, T. 1743. A letter concerning certain chalky tubulous concretions called malm; with some microscopical observations on the farina of the red lily, and of worms discovered in smutty corn. Philos. Trans. Roy. Soc. 42:173-174, 634-641.

Nordbring-Hertz, B., Jansson, H.B., and Tunlid, A., 2006. Nematophagous fungi. In: Encyclopedia of Life Sciences. John Wiley \& Sons, Ltd., Chichester. http://www.els.net.

Papavizas, G.C., Dunn, M.T., Lewis, J.A., and Beagle-Ristaino, J. 1984. Liquid fermentation technology for experimental production of biocontrol fungi. Phytopathology, 74:1171-1175.

Perry, N. 2010. The ecological importance of species and the Noah's Ark problem. Ecol. Econ. 69:478-485.

Peterson, H. and M. Luxton. 1982. A comparative analysis of soil fauna populations and their role in decomposition processes. Oikos. 39:287-388.

Poinar, G.O. Jr., Jansson, H.B. (Eds.). 1988. Diseases of Nematodes. vol. I and II. CRC Press, Boca Raton. FL, USA.

Sharon, E., M. Bar-Eyal, I. Chet, A. Herrera-Estrella, O. Kleifeld, and Y. Spiegel, 2001. Biological control of root knot nematode Meloidogyne javanica by Trichoderma harzianum. Phytopathology. 91:687-693.

Wang, D.Y-C., S. Kumar, and B.S. Hedges. 1999. Divergence time estimates for the early history of animal phyla and the origin of plants, animals and fungi. Proceedings of the Royal Society of London B 266:163-171.

Werner, B.J., T.M. Mowry, N.A. Bosque-Perez, H. Ding, and S.D. Eigenbrode. 2009. Changes in green peach aphid responses to potato leafroll virus-induced volatiles emitted during disease progression. Environ. Entomol. 38:1429-1438. 